\title{
An Evolving Road Map: Student Perceptions of and Contributions to Graphic Organizers within an Academic Wiki
}

\author{
Andrew Moshirnia \\ University of Kansas, Lawrence, KS, USA
}

Amoshirn@ku.edu

\begin{abstract}
Though the number of collaborative websites, or wikis, continues to grow, few studies have examined the role of graphics in a successful wiki design. This study examines the development of graphic organizers within an academic wiki over a period of 8 months. Wikis traditionally rely on a text-only approach to allow for user flexibility. However, this study found that the ability to easily add links to wiki navigation menus resulted in sprawl. Introduction of polished graphic organizers had a significant effect on user participation and their perception of the wiki.
\end{abstract}

Keywords: Web Based Learning, Collaborative Publishing, Graphic Organizers.

\section{Introduction}

Collaborative websites, or wikis, have attracted attention for their academic potential (Wang et al, 2005). By providing users with the means to engage in discovery learning and easily produce versatile online content, wikis engage learners who in turn enhance the wiki. However, the high learning curve for wiki editing and the text-only format of wiki articles can ward off potential users. This study examines the development of graphic organizers within an academic wiki over a period of 8 months. While previous studies have examined the use of academic wikis and the possible role of graphics as motivators (Moshirnia, 2007), this is the first case study of digital sprawl and student designed remedies within an academic wiki.

\section{Previous Research}

In this section I discuss the previous research related to graphic organizers, wikis, and the paucity of graphics in traditional wikis.

\section{Graphics as Organization Catalysts}

Graphic organizers have been shown to be effective in both digital and traditional pencil and pa-

Material published as part of this publication, either on-line or in print, is copyrighted by the Informing Science Institute. Permission to make digital or paper copy of part or all of these works for personal or classroom use is granted without fee provided that the copies are not made or distributed for profit or commercial advantage AND that copies 1) bear this notice in full and 2) give the full citation on the first page. It is permissible to abstract these works so long as credit is given. To copy in all other cases or to republish or to post on a server or to redistribute to lists requires specific permission and payment of a fee. Contact Publisher@InformingScience.org to request redistribution permission. per organization. Robinson (1995) found that college students form more detailed hierarchical relationships between concepts when they used graphic organizers than when they used outlines or texts alone. Alvermann (1981) also found that graphic organizers can compensate for a poorly organized text but facilitating a reorganization of information. Both of these findings have been supported by 
numerous subsequent experiments (Moshirnia, 2007). In the digital realm, Greene (2002) found that graphic organizers significantly increased the amount of collaboration between high school science students producing and presenting hypermedia research projects. Information graphics also improve user performance on the perceptual task of organizing by affording a better understanding of underlying principles and concepts of available data (Nowell, Schulman, \& Hix, 2002).

\section{Wikis}

The four main wiki characteristics are: (1) web documents to be authored collectively without individual ownership of the documents, (2) a simple markup scheme, (3) content is not reviewed by any editor or coordinating body prior to its publication, (4) maintains a temporal database enabling version management (Wagner \& Prasarnphanich, 2007). Wikis are typically textually based, with graphics used primarily as illustrations of article concepts, e.g. a picture of a bee in an article regarding honey.

In order to facilitate communal growth, wikis usually adopt a code of conduct which entails: "collaborative writing of shared pages, little individualism or ownership of content, instant publication of changes without editorial intervention, and the ability of users to roll-back pages (from the temporal database) in case of error or vandalism (Wagner \& Prasarnphanich, 2007).”

\section{Graphics in wikis}

Wikis usually do not rely on graphic-based organization (Moshirnia, 2007). Wikipedia, for example, uses only simple bullets for almost all of its navigation windows (Moshirnia, 2007). Consistent navigation graphics are used only in portal submenus and links to sister Wiki projects. Also, in-article organization almost never utilizes graphics. A user starting a new page typically encounters a blank screen or entry field. Jimmy Wales of the Wikipedia Foundation argues that these attributes create "a wiki learning curve" which "limits adoption." Further, Wales (Orlowski, 2005) expressed the fear that the technical knowledge needed for wiki editing is acting as a barrier for potential contributors.

\section{Experiment}

\section{Participants}

21 students $(\mathrm{N}=21)$ in the $10^{\text {th }}(\mathrm{n}=10)$ and $11^{\text {th }}(\mathrm{n}=11)$ grades participated in this study. They were enrolled in $1^{\text {st }}$ and $2^{\text {nd }}$ year Latin at a sub-urban high school located in the Great Plains region of the United States. Participants ranged in age from 15 to 17, with the mean age of 16.2. The sample was comprised of roughly equal numbers of males $(n=11)$ and females $(n=10)$. The sample was racially diverse, comprising 2 African-Americans $(\mathrm{n}=2), 1$ Asian $(\mathrm{n}=1)$, and 18 Caucasian $(\mathrm{n}=18)$ students. The students used an academic wiki for 6 months. Students were then asked to author papers explaining how the paper could be improved. 17 of these students were then asked to use an academic wiki with added graphics (Moshirnia, 2007). The students who participated in this study were given credit.

\section{SPQR4EVA}

The wiki is named SPQR4eva, a phrase which denotes both its subject matter and approach to pedagogy. SPQR, is an initialism of the Latin "Senatus Populusque Romanus", which may be translated as "The Senate and People of Rome." 4eva is internet slang for the word "forever." SPQR4eva would be read as "Rome Forever" by individuals with knowledge of Latin and internet slang, such as the participants in this study. 


\section{Data Collection}

The wiki survey comprised 24 items on a 5-point Likert Scale and 6 free response questions. Following the survey, students were asked to prepare an essay explaining how the wiki should be changed. Following this period, icons were added to the wiki. Subjects then reexamined SPQR4EVA and were given a likert item survey to assess their impression of the wiki.

\section{Evolution of organization systems}

Due to the ever increasing number of articles on the wiki and the breadth of content within individual articles, it was a constant struggle to maintain an effective organization scheme for articles and in-article information. This section traces the evolution of both in-article and site wide organization systems, from a text-based list format to icon aided graphic organizers.

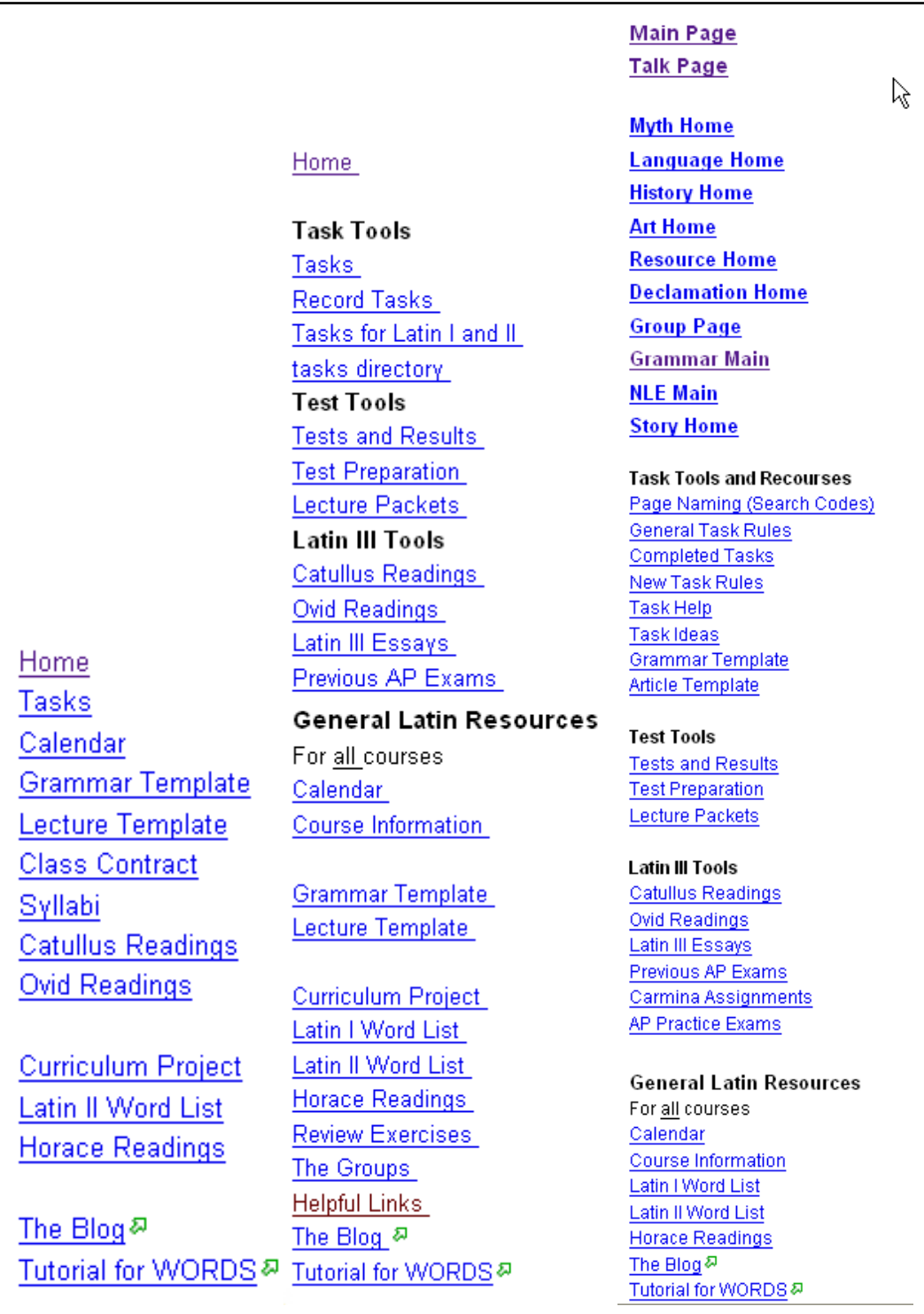

Figures 1, 2, and 3 (from left to right: Navigation bars show the site wide organization of SPQR4eva at Aug. $2^{\text {th }}$, Nov, $5^{\text {th }}$, and April $3^{\text {rd }}$. 
The navigation bar for the wiki originally contained no icons and consisted of 14 links. This organizational scheme was created to mirror the navigation bar used by Wikipedia, the most widely known wiki site. The tool bar used spaces as organizational constraints to create 3 categories, with links grouped by in-class tools, project resources, and outside links.

Subjects were allowed to alter the navigation bar as they saw fit. The first changes were the introduction of explicit section separators. Rather than relying on blank space to delineate sections, users added enlarged text. This made it easier to discern the logic behind link groups but also increased the number of items within the tool bar. Approximately 100 days into the experiment, the tool bar had grown to include 25 links and 6 categories: Home, Task Tools, Test Tools, Latin III tools, General Resources, Templates, and Other. The toolbar was suffering from sprawl and caused an increased cognitive load by including so many items and subdivisions, as shown in Figures 1, 2, and 3 .

Though subjects recognized the difficulty of using an enlarged navigation bar, they continued to add links and categories. By April $3^{\text {rd }}$, the toolbar had swollen to 36 links and 6 categories. It was at this time that the navigation bar was locked to outside changes. Subjects were asked to assess the effectiveness of the toolbar and suggest improvements. Following this meeting, the entire toolbar was redesigned to include: 1) fewer links 2) graphic organization aided by icons, as seen in Figures 4 and 5, and 3) fewer categories.

The subsequent navigation bars have the unusual addition of nested graphics. While this design is unorthodox for wikis, it was positively received by subjects and helped resolve organizational

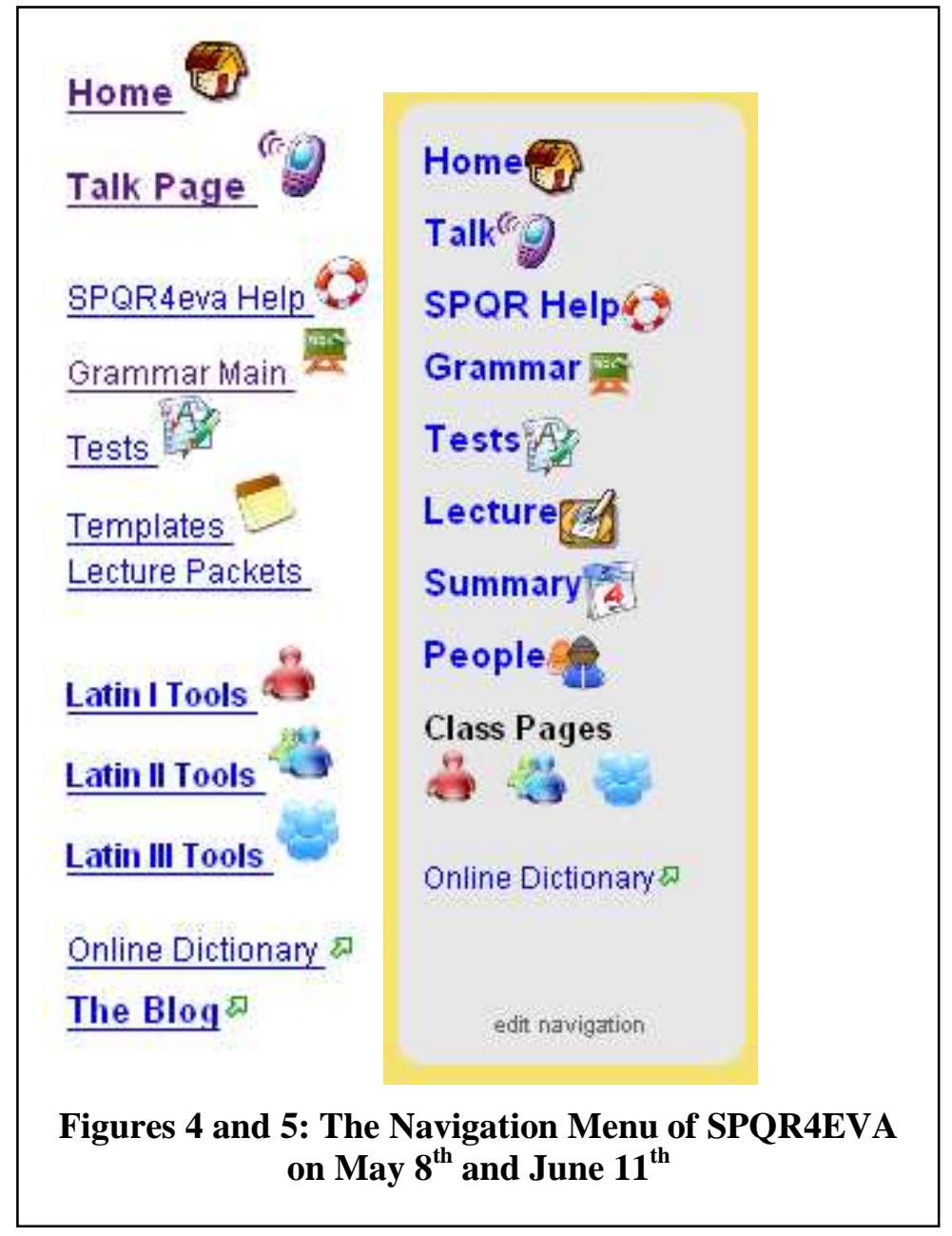


issues. The last two iterations of the navigation bar include 12 and 11 links respectively, with the final iteration needing only 3 categories of links: Tools, Class Pages, and Outside Links. A summary of the use of icons, links, and categories in the navigation bar is presented in Table 1.

Table 1: A summary of Navigation Bar Contents

\begin{tabular}{|c|c|c|c|}
\hline Date & Icons & Links & Categories \\
\hline $8-20$ & $\mathbf{0}$ & 14 & $\mathbf{3}$ \\
\hline $11-05$ & 0 & 25 & 6 \\
\hline $4-03$ & 0 & 36 & 6 \\
\hline $5-08$ & 9 & 12 & 4 \\
\hline $6-11$ & 11 & 11 & 3 \\
\hline
\end{tabular}

\section{In-article organization}

No formatting instructions for in-article organization were given at the beginning of this experiment. Users who started a page were not given the choice of using a pre-constructed template. Without a predetermined format, early articles suffered from a lack of organization. For example, an article on the $1^{\text {st }}$ conjugation did not have a table of contents, nor any headings or subheadings to break down concepts, as seen in Figure 6.

\section{1st Conjugation Verbs}

Edit This Page

Verbs in the first conjugation all have an infinitive ending in -are (e.g. amare, lavare, etc.), and can thus be recognised. The verb I'll use as an example for the 1st conjugation declension endings will be amo, the verb to love, whose principle parts are amo, amare, amavi, and amatus. Indicative:

\begin{tabular}{|r|r|}
\hline & Active Passive \\
\hline Present 1st sing. am-o am-or \\
\hline 2nd sing. am-as am-aris \\
3rd sing. am-at am-atur \\
\hline
\end{tabular}

1st plural

|| am-amus || am-amur ||

Figure 6: An Article without a Table of Contents or much Graphic Organization

Subjects improved the organizational scheme by using table of contents based on headings and later incorporating graphics to organize content, as seen in Figures 7 and 8. 


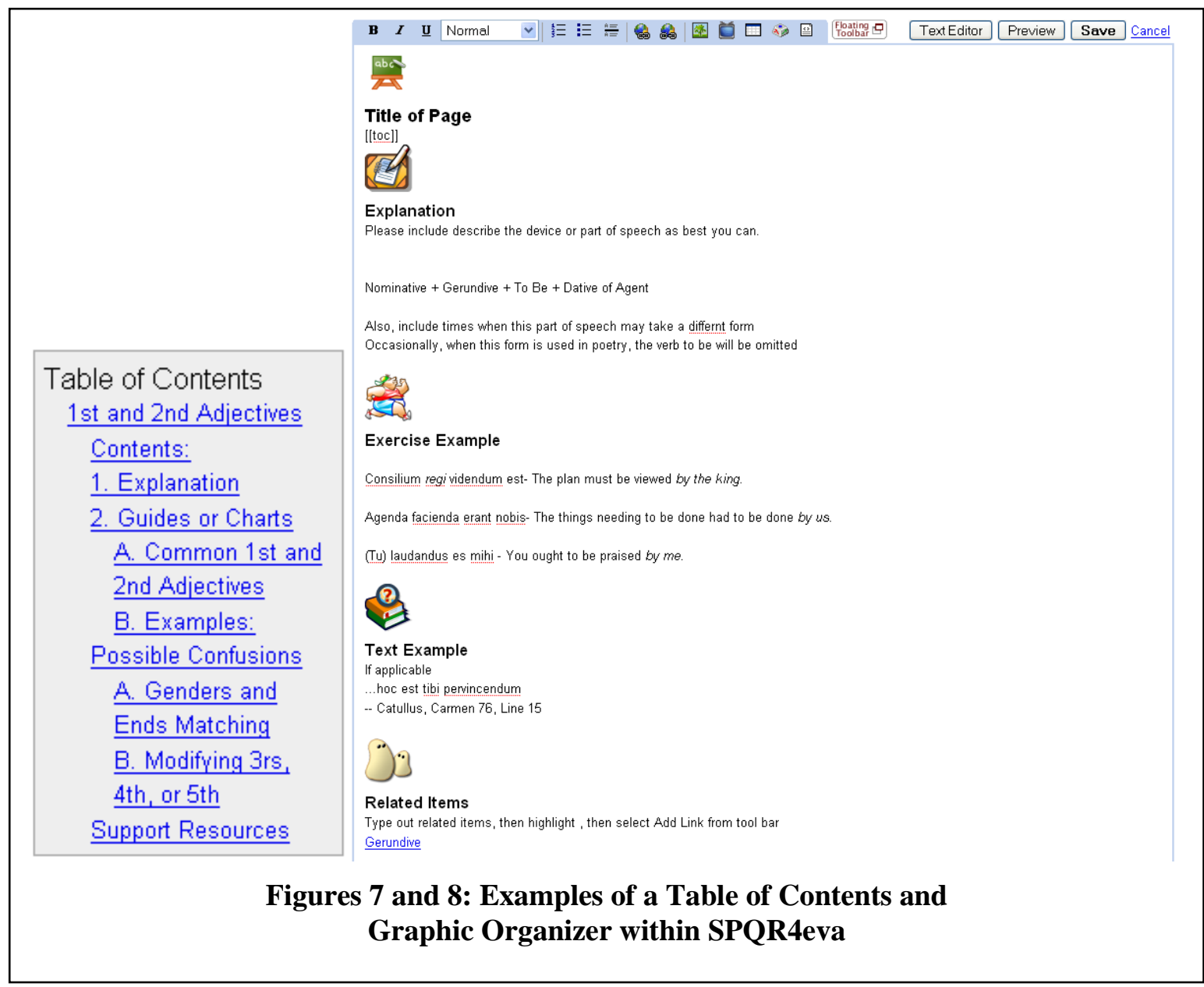

\section{Need for graphics}

Several students anticipated the need for graphic organization, stating "in order to maximize the effect of the wiki, a complete structural redesign, followed by some pretty colors and pictures would go a long way." The wiki was considered "boring; it's white with little black letters all over it. The wiki needs more pictures... anything with color is good, just put something there. Even political sites have some color (and that says a lot because politics are pretty boring)."

\section{Lack of organization}

The most common complaint regarding the wiki was a lack of organization or a poor organization scheme. Specifically, the navigation tool bar "has grown too large to be of use... [it] was originally a good idea ... however, the toolbar has been continually added on, until it is difficult to find the right thing." Or more simply "when I go to the wiki I don't understand were to go."

\section{Quantitative Results}

A single sample $t$ test was conducted on the survey items, "The Wiki is easier to use with graphics" and "I am more likely to use a wiki if it has graphics". Both tests returned significant values, indicating that graphics play an important role in wiki organization and user motivation. A summary of these results may be seen in Table 2. An earlier analysis of this data focused on the interaction between rules systems and graphic organizers in motivating students (Moshirnia, 2007). 


\begin{tabular}{|l|r|r|r|r|}
\hline \multicolumn{6}{|c|}{ Table 2: Impact of Graphics on Perception of Wiki } \\
\hline QUESTION & MEAN & SD & N & SIGNIFICANCE \\
& & & & \\
\hline "Wiki is easier..." & 4.47 & .717 & 17 & .001 \\
\hline "Likely to use" & 3.82 & .727 & 17 & .001 \\
\hline
\end{tabular}

Subjects perceived a wiki with graphics more positively than a wiki without graphics. A common complaint in student assessments of the text only wiki was that it was visually monotonous or boring. Subjects expressed a greatly willingness to use a wiki which included exaggerated or cartoonish icons in its menu and pages (Moshirnia, 2007).

A single sample $t$ test was conducted on the survey item "I prefer the graphics on the wiki to be..." Subjects preferred the exaggerated/cartoonish graphics to the realistic/serious graphics by a significant margin. A summary of this data is presented in Table 3.

\begin{tabular}{|c|c|c|c|c|}
\hline \multicolumn{6}{|c|}{ Table 3: Student Preference of Exaggerated/ } \\
Cartoonish Graphics \\
\hline QUESTION & Mean & SD & $\mathbf{N}$ & SIGNIFICANCE \\
& & & & \\
\hline "I prefer the graphics..." & 1.59 & 1.12 & 17 & .001 \\
\hline
\end{tabular}

\section{Wiki statistics after introduction of graphics}

The collection of usage statistics after the introduction of new graphics was disrupted by the end of the school year. The short collection time removes the opportunity for statistical analysis of these data, however the short term results are encouraging as the number of views and unique visitors increased. The number of daily views increased from an average of 80 to 128.3, while the number of unique visitors increased from an average of 9.7 to 14.7 (Moshirnia, 2007). A summary of this data is presented in Table 4.

\begin{tabular}{|l|r|r|}
\hline \multicolumn{3}{|c|}{ Table 4: Impact of Graphics on Wiki Use } \\
\hline \multicolumn{1}{|c|}{ TIME SPAN } & $\begin{array}{c}\text { AVERAGE } \\
\text { DAILY VIEWS }\end{array}$ & $\begin{array}{c}\text { AVERAGE } \\
\text { UNIQUE USERS }\end{array}$ \\
\hline $\begin{array}{l}\text { 3 days before } \\
\text { Graphic Introduction }\end{array}$ & 80 & 9.7 \\
\hline 3 days following Graphic Introduction & 128.3 & 14.7 \\
\hline
\end{tabular}

Students expressed their gratitude for the addition of graphics to the wiki (Moshirnia, 2007). "Kudos to whoever made the wiki beautiful. I like it. It brightened my day. :)." Several students commented that the exercise icon "is funny and makes me feel a little better. That is what I need, something funny to cheer me up when I am studying..." 


\section{Conclusion}

Proponents of wikis often tout the versatility of the platform and the freedom it affords users. However, this case study suggests that this freedom can lead to digital sprawl. Users contributing new articles were inclined to add links to the navigation bar of the entire wiki. This usergenerated feature creep had a significant impact on the utility of the wiki. Users indicated that they could no longer navigate the wiki and easily became lost. In-page navigation also suffered, since pages tended to have neither a table of contents nor a system of organization. The introduction of graphics stabilized the navigation menu for the wiki and provided an organizational scheme for pages.

Graphics may aid wiki users by delimiting the editing field and guiding the user to areas of interest. The text-only or text-centered design of most wikis provides no such boundaries. Users may appreciate the added support of graphics or simply be unwilling to delete graphics which have been posted. It is important to note that no new navigation links or navigation icons were introduced after graphic organizers were added to the navigation bar. It is hard to say if this occurred because of user satisfaction or because of the difficulty of creating graphic links in navigation menus. It is possible that a root user could prevent sprawl in a wiki simply by denying lower-level users the ability to edit navigation menus. However, this approach would ignore user preferences for attractive graphics.

The use of graphics in navigation menus and in-page organizers in a wiki is not an absolute necessity. Wikipedia, which has only just begun incorporating more graphics for navigation, has succeeded in a text-centered format. However, comparing Wikipedia to most academic wikis seems foolish. Wikipedia employs a dedicated staff of editors to clean up and order articles, and is not very concerned with the cognitive load of menus. As of Early 2008, the running menu of Wikipedia hosts 87 links to different content lists, discussion boards, tools, and languages. It would be worth investigating how often a user finds a desired article using navigation tools within Wikipedia as compared to how often an outside search engine, such as Google, is used.

While graphics may not be required to create a successful wiki, early results indicate that users are more likely to use a wiki which makes use of icons in graphic organizers. Though the content of a wiki is the prime concern of educators, designers of academic wikis should not ignore the important role of decoration and aesthetic in recruiting both users and contributors. At the same time, the difficulty of producing and nesting icons may force users to make more thoughtful edits to the navigation menus of communal wikis.

\section{Questions for further study}

While subject perceptions are important, the actual effectiveness of graphic organizers within wikis should be examined. Future studies should measure the time needed to complete searching tasks in traditional and graphically enhanced wikis. This paper was concerned only with group designed graphic organizers for use in wikis. Future studies should examine the role of graphic organizers within personal wikis, as well as the importance of wiki editors (Wiki text vs.

WYSIWYG) in facilitating the use of graphic organizers.

\section{References}

Alvermann, D. (1981). The compensatory effect of graphic organizers on descriptive text. Journal of Educational Research, 75(1), 44-48.

Greene, J. P. (2001). Effects of graphic organizers on high school science students' collaborative production and presentation of hypermedia research projects. Doctoral Dissertation, University of South Florida, USA, College of Education. Florida. 
Moshirnia, A. (2007). Important ornaments: The impact of graphics and rule systems on academic wiki use. Proceedings of Interactive Computer Learning 2007

Nowell, L., Schulman, R., \& Hix, D. (2002). Graphical encoding for information visualization: An empirical study. IEEE Symposium on Information Visualization, 2002. INFOVIS 2002, 43-50.

Orlowski, A. (October 2005). Wikipedia founder admits to serious quality problems. The Register. Retrieved from http://www.theregister.co.uk/2005/10/18/wikipedia_quality_problem/

Robinson, D., \& Kiewra, K. (1995). Visual argument: Graphic organizers are superior to outlines in improving learning. Journal of Educational Psychology, 87(3), 455-67.

Wagner, C., \& Prasarnphanich, P. (2007). Innovating collaborative content creation: The role of altruism and wiki technology. Proceedings of $40^{\text {th }}$ Hawaii International Conference on System Sciences.

Wang, H., Lu, C., Yang, J., Hu, H., Chiou, G., Chiang, Y., \& Hsu, W. (2005). An empirical exploration of using wiki in an English as a second language course. Advanced Learning Technologies, 2005. ICALT 2005. Fifth IEEE International, 155-157.

\section{Biography}

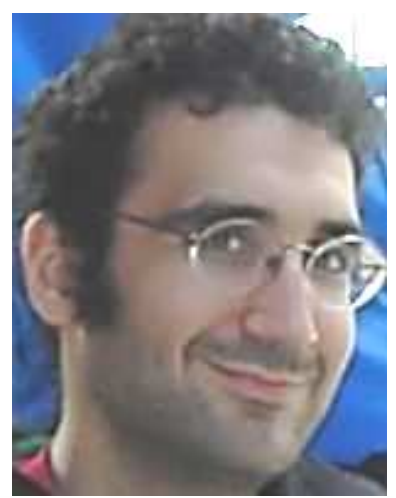

Mr. Andrew Moshirnia is pursuing his Doctorate in Educational Technology at the University of Kansas. His research interests include ludic motivation, game modification, and the instruction of classical languages. 